\title{
Transforming the lecture-hall environment: The fully interactive physics lecture
}

\author{
David E. Meltzer \\ Kandiah Manivannan \\ Missouri State University
}

Follow this and additional works at: https://bearworks.missouristate.edu/articles-cnas

\section{Recommended Citation}

Meltzer, David E., and Kandiah Manivannan. "Transforming the lecture-hall environment: The fully interactive physics lecture." American Journal of Physics 70, no. 6 (2002): 639-654.

This article or document was made available through BearWorks, the institutional repository of Missouri State University. The work contained in it may be protected by copyright and require permission of the copyright holder for reuse or redistribution.

For more information, please contact BearWorks@library.missouristate.edu. 


\title{
Transforming the lecture-hall environment: The fully interactive physics lecture
}

\author{
David E. Meltzera) \\ Department of Physics and Astronomy, Iowa State University, Ames, Iowa 50011 \\ Kandiah Manivannan \\ Department of Physics, Astronomy, and Materials Science, Southwest Missouri State University, \\ 901 South National Avenue, Springfield, Missouri 65804
}

(Received 19 September 2001; accepted 29 January 2002)

\begin{abstract}
Numerous reports suggest that learning gains in introductory university physics courses may be increased by "active-learning" instructional methods. These methods engender greater mental engagement and more extensive student-student and student-instructor interaction than does a typical lecture class. It is particularly challenging to transfer these methodologies to the large-enrollment lecture hall. We report on seven years of development and testing of a variant of Peer Instruction as pioneered by Mazur that aims at achieving virtually continuous instructorstudent interaction through a "fully interactive" physics lecture. This method is most clearly distinguished by instructor-student dialogues that closely resemble one-on-one instruction. We present and analyze a detailed example of such classroom dialogues, and describe the format, procedures, and curricular materials required for creating the desired lecture-room environment. We also discuss a variety of assessment data that indicate strong gains in student learning, consistent with other researchers. We conclude that interactive-lecture methods in physics instruction are practical, effective, and amenable to widespread implementation. (C) 2002 American Association of Physics Teachers.
\end{abstract}

[DOI: 10.1119/1.1463739]

\section{INTRODUCTION}

Numerous investigations in recent years have shown active-learning methods to be effective in increasing student learning of physics concepts. These methods aim at promoting substantially greater engagement of students during inclass activities than occurs, for instance, in a traditional physics lecture. A long-standing problem has been that of transporting active-learning methods to large-enrollment classes in which 50-300 students sit together in a single classroom.

An important breakthrough in addressing this problem was the 1991 introduction of the Peer Instruction method by Eric Mazur at Harvard University. ${ }^{1}$ This now widely adopted method restructures the traditional lecture class into a series of short lecture presentations punctuated by a series of "ConcepTests." These are qualitative multiple-choice questions to which all students in the class simultaneously respond, both before and after discussion.

In this paper we describe a variant of Peer Instruction that we have developed and tested. It carries the transformation of the physics lecture-room environment several steps further, aiming at the achievement of a virtually continuous dialogue between students and instructor of a type ordinarily characteristic only of one-on-one (or one-on-few) instruction that takes place, for example, in the instructor's office with a handful of students present. This "fully interactive lecture" offers a useful option for physics instructors who want to maximize the potential for instructor-student interaction in the large-classroom environment. We have employed these methods in our classes over the past seven years at Southeastern Louisiana University (SLU), the University of Virginia, Iowa State University (ISU), and Southwest Missouri State University.
The basic elements of an interactive lecture strategy have been described by Mazur. ${ }^{1}$ In this paper we broaden and extend that discussion, explaining in detail how the lecture component in large-classroom instruction may be almost eliminated. Depending on the preferences of the instructor and the specific student population, this strategy may yield worthwhile learning outcomes. To carry out the rapid backand-forth dialogue observed in one-on-one instruction in large-enrollment classes requires a variety of specific instructional strategies, an unusual form of preparation by the instructor, and specific characteristics of the curricular materials.

In Sec. II we review the research related to student learning in physics lecture classes. In Sec. III we give an overview of our general strategy for creating interactive lectures, and the student response systems necessary to that strategy are discussed in Sec. IV. In Sec. V we outline the format of the fully interactive lecture class, while Sec. VI contains a detailed, almost verbatim, excerpt from an actual class. This excerpt is analyzed in Sec. VII. In Sec. VIII we discuss the printed curricular materials that have been developed for use with these instructional methods. In Sec. IX we discuss implementation issues, and in Sec. $\mathrm{X}$ we discuss the analysis of assessment data related to student learning in our classes. We offer some concluding remarks in Sec. XI.

\section{A LONG-STANDING CHALLENGE: PROMOTING ACTIVE-LEARNING IN LARGE LECTURE CLASSES}

\section{A. Motivation: Student-instructor disconnect in large-enrollment classes}

Recent research has cast serious doubt on the effectiveness of instruction for the majority of students enrolled in intro- 
ductory physics courses, the most common setting for largeenrollment, lecture-based instruction. Not surprisingly, the large-enrollment lecture class is among the most challenging environments in which to achieve improved learning gains. It is very difficult for instructors to assess student learning and to implement any needed alterations in instruction in "realtime." Moreover, the high student/instructor ratio makes it difficult for instructors to engage students in instructional activities that go much beyond passive listening.

\section{B. Limitations of the lecture approach: The case of physics}

An increasing body of evidence suggests that instruction utilizing only lecture classes and standard recitations and labs results in relatively small increases in most students' understanding of fundamental concepts. ${ }^{2-8}$ Complex scientific concepts are often not effectively communicated to students simply by lecturing about them-however clearly and logically the concepts may be presented. ${ }^{9-12}$ Students taught exclusively through lecture-based curricula are inclined to short-circuit the highly complex scientific thought process. $^{13,14}$ Lectures that are particularly clear and wellorganized may, ironically, contribute to students' tendency to confuse the results of science with the scientific process itself. Students who avoid the intense mental struggle that often accompanies growth in personal understanding may never succeed in developing mastery over a concept. ${ }^{15}$ In other words, students do not absorb physics concepts simply by being told (or shown) that they are true, and they must be guided to resolve conceptual confusion through a process that maximizes the active engagement of their mental faculties.

A term that is often used to characterize an instructional process of this type is "active learning," and the term "interactive engagement" (IE) has been used to describe the type of physics instruction that most effectively engenders active learning through discussion with peers and/or instructors. ${ }^{4}$ Active learners are relatively efficient at learning physics concepts. They are perhaps most easily characterized as students who continuously and actively probe their own understanding in the process of learning new concepts. They frequently formulate and pose questions to themselves, constantly testing their knowledge. They scrutinize implicit assumptions, examine systems in varied contexts, and are sensitive to areas of confusion in their understanding. By contrast, the majority of students in introductory physics courses are unable to do efficient active learning on their own. In essence, they don't know the questions they need to ask. They are often unable to recognize when their own understanding is inadequate, and tend to lack confidence in their ability to resolve confusion. In order to carry through the learning process effectively, they require substantial guidance by instructors and aid from appropriate curricular materials.

There is good evidence that, in addition to improving learning by students who may not be natural active learners, interactive-engagement methods result in significant learning gains by the best students as well. ${ }^{16,17}$ Pedagogical models that engage students in a process of investigation and discovery - often oriented around activities in the instructional laboratory-are specific types of interactiveengagement methods found to be effective. ${ }^{5,6,10,17-20}$ The targeted concepts are in general not told to the students before they have the opportunity to follow through chains of rea- soning that might lead them to synthesize the concept on their own. It is especially challenging to develop effective active-learning methods that lack a laboratory component, and the large lecture class is an inherently difficult environment in which to establish active learning.

\section{Recent approaches to active learning in large physics lecture classes}

The issue of how to increase attention and engagement of students during lecture courses is not unique to physics. Various systems have been designed that allow students in large classes to provide instantaneous responses to instructors' questions. $^{21-23}$ Other influential methods include "think-pair-share" 24 (periodic interruption of lectures for student discussion), and the "minute paper" 25 (students' written comments during the last minute of class). Various strategies have been reviewed by Bonwell and Eison. ${ }^{26}$

Physics educators have explicitly addressed the challenge of the large-class learning environment. Van Heuvelen ${ }^{27,28}$ has developed "active-learning problem sheets" 29,30 for student use during class meetings in the lecture hall. ${ }^{31}$ Mazur has achieved great success in popularizing Peer Instruction ${ }^{1,32-35}$ by suspending a lecture at regular intervals with challenging conceptual questions posed to the whole class. Other early strategies for lecture classes have been described. ${ }^{36-38}$ More recently, the group at the University of Massachusetts has developed and popularized interactivelecture methods employing an electronic response system. ${ }^{39-41}$ Poulis et al. $^{42}$ have also made use of interactive lecturing with an electronic system, and other electronic communication systems for use in lectures have been discussed by Shapiro, ${ }^{43}$ and by Burnstein and Lederman. ${ }^{44}$

Other strategies for implementing active learning in largeenrollment classes have been described by Beichner et al. ${ }^{45}$ and by Zollman. ${ }^{46}$ Sokoloff and Thornton have adapted their very popular microcomputer-based laboratory materials, originated in collaboration with Priscilla Laws, , 18,47 for use in large lecture classes in the form of "interactive lecture demonstrations." "48,49 Assessment data from several groups support the effectiveness of this method. ${ }^{6,17,18}$ Novak and collaborators ${ }^{50}$ have developed the "just-in-time teaching" method in physics lecture courses, incorporating some techniques similar to those used by Hestenes and his collaborators in the "modeling instruction" 51 method. Textbooks and workbooks with a high interactive component, usable in large classes, include those by Chabay and Sherwood ${ }^{52,53}$ and by Knight. ${ }^{54}$ There is good evidence for the effectiveness of both of these innovative curricular materials. ${ }^{55,56}$ The interactive-lecture strategies to be discussed in this paper build on the recent history of efforts to improve instruction in large physics classes. Preliminary reports have been published, ${ }^{57,58}$ and several workshops have been presented. ${ }^{59}$

Other important pedagogical reform methods focus more particularly on activities that occur in small-class laboratories or recitation sections associated with lecture courses. Among the most prominent are the Tutorials in Introductory Physics, ${ }^{60,61}$ Collaborative Group Problem Solving, ${ }^{62-65}$ and RealTime Physics, ${ }^{66}$ along with its close relative, Workshop Physics. ${ }^{67}$ Important research results related to instruction in large-enrollment physics classes have been reported by Kraus, ${ }^{68}$ and Cummings et al. ${ }^{17}$ have described a careful investigation of a technology-rich studio environment. ${ }^{69}$ 


\section{TRANSFORMING THE LECTURE-ROOM ENVIRONMENT}

Our goal is the transformation of the lecture class, to the furthest extent possible, to the type of instructional environment that exists in an instructor's office. When physics instructors have one or two students in their office, they would likely speak for just a few minutes, solicit some feedback, then continue the discussion based on that feedback. In the office, instructors can get a sense of where students are conceptually and of how well they are following the discussion. It is possible to tailor one's presentation to the students' actual pace of understanding. By asking students to consider each other's ideas, the instructor helps them to think critically about their own ideas. The key issue is whether it is practical to do this in a room filled with 100 or more students.

We (and others) have found that it is practical to bring about this transformation to a very great extent. Success hinges on two key strategies: (1) students need to be guided in a deliberate, step-by-step process to think about, discuss, and then respond to a carefully designed sequence of questions and exercises; (2) there must be a system for the instructor to obtain instantaneous responses from all of the students in the class simultaneously. This system allows instructors to gauge their students' thinking and to rapidly modify their presentation, subsequent questioning, and discussion of students' ideas. Our methods are a variant of Peer Instruction, ${ }^{1,32-35}$ and are similar to methods used at the University of Massachusetts ${ }^{39-41}$ and at Eindhoven. ${ }^{42}$

The basic objective is to drastically increase the quantity and quality of interaction that occurs in class between the instructor and the students and among the students themselves. To this end, the instructor poses many questions. Students decide on an answer, discuss their ideas with each other, and provide their responses using a classroom communication system. The instructor makes immediate use of these responses by tailoring the succeeding questions and discussion to most effectively match the students' pace of understanding.

In attempting to address the insufficiencies of the traditional lecture, the fully interactive lecture method that we employ essentially abandons any effort to utilize class time for presenting detailed and comprehensive explanations and derivations of physics principles. Instead, that time is used in much the same way as in one-on-one tutoring: there is a continual interchange of questions and answers between instructor and students. The instructor guides the students in step-by-step fashion to consider certain problems; the students listen, think, write or calculate, and then receive immediate feedback regarding the correctness of their responses, both from their classmates and from the instructor.

In abandoning lecture's traditional role of providing extensive and detailed background information, we must evidently utilize other means for achieving that objective. The burden of providing a detailed compendium of facts, derivations, and explanations is carried by a set of lecture notes; these largely substitute for the traditional textbook. Students are expected to read and refer to the lecture notes for background information and sample problems. Although we do review during class the concepts developed in the lecture notes, we do not find it productive to spend extensive amounts of time on that activity.

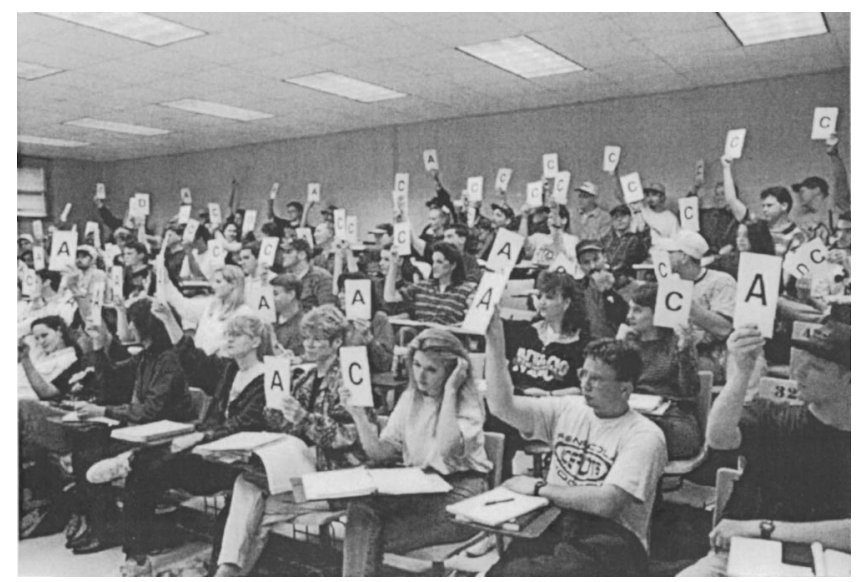

Fig. 1. Students signaling their response to instructor's question using flash cards.

\section{STUDENT RESPONSE SYSTEM}

There are a number of student response systems available for use with interactive-lecture methods, including commercially available electronic systems. ${ }^{70-72}$ Our method employs flash cards on which oversize letters of the alphabet are printed. Flash cards are less expensive and easier to implement, although they lack useful features of the electronic systems such as instant graphical displays of responses. We emphasize that almost everything we discuss in this paper may be implemented equally effectively with electronic response systems.

With the use of the flash-card system, we are able to ask many questions during class and no longer have to wait for one daring individual to respond. Every student in the class has a pack of six large cards $\left(5 \frac{1}{2} \mathrm{in} . \times 8 \frac{1}{2}\right.$ in.), each printed with one of the letters A, B, C, D, E, or F. Students bring the cards every day, and extra sets are always available. During class we repeatedly present multiple-choice questions. Often, the questions stress qualitative concepts involving comparison of magnitudes, directions, or trends (for example, "Will it decrease, remain the same, or increase?"). These questions are difficult to answer by plugging numbers into an equation. We give the students time to consider their response, $15 \mathrm{~s}$ to 1 min depending on the difficulty. Then we ask them to signal their response by holding up one of the cards, everybody at once (see Fig. 1). We can easily see all the cards from the front of the room. Immediately, we can tell whether most of the students have the answer we were seeking-or if, instead, there is a "split vote," that is, part of the class with one answer, part with another-or perhaps more than one other. (One of them, it is hoped, is the right answer!)

One of the advantages of this system is that it allows the instructor to observe the students' body language. We can see whether the students held up their cards quickly, with confidence, or if instead they brought them up slowly, with confused looks on their faces. Do a large number of students delay their response, finally holding up an upside-down F? This is our signal for "I don't really know the answer, and I can't even give a very good guess." It is not particularly easy for students to see each others' cards and so there is a fair degree of anonymity in their responses. Students' comfort in signaling answers with the cards seems to increase as the course progresses. 


\section{FORMAT OF THE FULLY INTERACTIVE LECTURE CLASS}

\section{A. Overview}

Although there is considerable flexibility in the actual format of a fully interactive lecture class, it is possible to describe a characteristic pattern. The actual length and sequencing of the individual phases will vary depending on the activities of the previous class and those planned for the succeeding days. A typical class proceeds in three phases.

(1) A brief introduction/review of the basic concepts is presented at the blackboard, a sort of mini-lecture usually lasting around 3-7 min.

(2) A sequence of multiple-choice questions is posed to the class. These emphasize qualitative reasoning, proceeding from relatively simple to more challenging, and are closely linked to each other to explore just one or two concepts from a multitude of perspectives, using a variety of representations. ${ }^{73}$ Students provide responses by using the flash cards. Every opportunity is taken to interrupt the sequence of multiple-choice questions with brief free-response exercises, for example, drawing simple diagrams or performing elementary calculations. ${ }^{74}$

(3) Follow-up activities are carried out. These vary and may consist of interactive demonstrations, group work using free-response worksheets, or another mini-lecture and question sequence.

At ISU, in addition to the class meetings $(3 \mathrm{~h} /$ week $)$ in the lecture hall, we make use of a once-per-week 50-min recitation session, which has been converted into a full-fledged tutorial in the style developed at the University of Washington. ${ }^{10,60}$ Students spend the entire session working in small groups on carefully structured printed worksheets, guided by Socratic questioning from the instructors. Worksheets used in these tutorials have been designed by us and also form part of the Workbook for Introductory Physics. ${ }^{75}$ At ISU we also have been able to make use of four of the weekly, 2-h laboratory periods to do additional activelearning instruction. In these we use Tutorials for Introductory Physics ${ }^{61}$ and materials from the text Electric and Magnetic Interactions. ${ }^{52}$

\section{B. Mini-lecture}

The instructor begins by taking a few minutes to outline the principles and concepts underlying that day's activities. One or two key ideas are sketched, along with relevant diagrams and mathematical formulations. A demonstration might be shown (soliciting students' predictions of the outcome) and an example problem solved at the board. From then on the ball moves to the students' court.

\section{Interactive-question sequence}

The instructor proceeds to ask a series of questions to which the students all respond. We might use questions printed in the Workbook (which students always bring to class $^{76}$ ) or present questions on the board or with an overhead transparency. The sequence starts with easy questions, in order to build confidence. Students consider the question on their own, taking perhaps $15-30 \mathrm{~s}$. At a certain moment, all are asked to give their responses simultaneously. Because the first few questions are simple, the responses should be overwhelmingly correct. Gradually, the questions become more challenging. The instructor takes any available oppor-

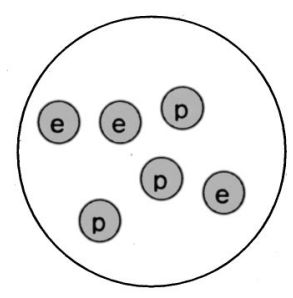

(a)

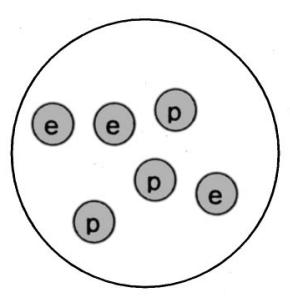

(b)

Fig. 2. Diagrams used in interactive-question sequence: (a) initial diagram, requiring flash-card response; (b) follow-up diagram, requiring free response by students writing at their desks.

tunity to interject a question requiring a "free response," such as a simple sketch. As the students work on the freeresponse questions, the instructor circulates around the room and observes their work.

As an example, the diagram in Fig. 2(a) was presented to the class ( $e$ represents an electron, $p$ a proton). Students were first asked about the net electrical charge on the object represented by the circle; is it (A) greater than zero, (B) equal to zero, or (C) less than zero. Most students quickly responded with the correct answer, B. The instructor then drew in a nearby positive charge [Fig. 2(b)], inviting students to consider the nature of the interaction between the circled object and the positive charge (assuming the electrons and protons are fixed in position). He asked the students to sketch a set of arrows representing all electrical forces acting on that positive charge due to each of the protons and electrons. As the students worked at their desks, the instructor walked around the room, and quickly assessed how well the students were handling the assignment; he stepped to the board for a few moments to offer some hints. This entire process took less than $1 \mathrm{~min}$. The instructor then asked the students whether the net interaction force implied by the collection of force vectors they had drawn was (A) toward the right, (B) toward the left, or $(\mathrm{C})$ approximately equal to zero.

As an example of a more extended sequence, consider the series of electric field questions in Fig. 3. Question 1 is fairly easy; a large majority of students gave the correct answer (B) without needing to discuss it with their neighbors. When we came to question 2, however, we found that students were split in their choices; in addition to the correct answer (B), a significant fraction of the class held up the A card. When we came to question 3 , the class response was very split; each of the options received some support. (Later, question 4 was given as a follow-up question in a different context.)

At some point, there is likely to be a significant split in opinion reflected in the students' responses. Perhaps 50\%$70 \%$ give one answer (for example, A), while the remainder give a different answer (let's say, C). The instructor informs 
1. An electron is placed at the origin, and then released and allowed to move freely. It begins to move along the positive $x$ axis. From this one can conclude that the electric field at the origin points:
A. toward the positive $\mathrm{x}$ direction
B. toward the negative $\mathrm{x}$ direction
C. toward the positive $y$ direction.
D. toward the negative $y$ direction.
E. in a direction not along either $\mathbf{x}$ or $\mathbf{y}$ axes.
F. There is not enough information to determine the direction of the electric field at the origin.

2. In a certain region of space, the electric field is zero everywhere. This means that, if a charged particle is located anywhere in this region:

A. the particle can not be moving.

B. the particle experiences no net electrical force.

C. the particle experiences a repulsive electrical force.

D. the particle experiences an attractive electrical force.

E. the particle is always forced back toward one particular location.

3. Throughout a certain region of space, the electric field has uniform magnitude and direction. This means that wherever a particular charged particle is placed at rest in this region and then allowed to move freely, it will always:

i. remain motionless.

ii. move with constant speed.

iii. move in an unchanging direction.

iv. move with constant magnitude of acceleration.

A. i only

B. ii only

C. ii and iii only

D. iii and iv only

4. Charge $\mathrm{A}$ is $2 \mathrm{C}$ and charge $\mathrm{B}$ is $-4 \mathrm{C}$. They are sitting in a uniform electric field. Which of these diagrams correctly shows the forces that are exerted on charges $\mathrm{A}$ and $\mathrm{B}$ by the electric field (not by each other)?

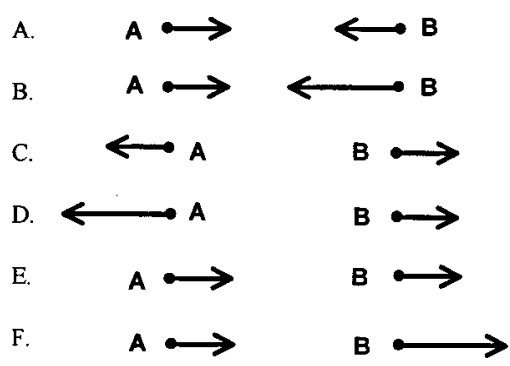

Fig. 3. Excerpt from interactive-question sequence.

the class of the difference of opinion: "We have A's and C's, perhaps a few more A's. Why don't you take a few seconds to discuss it with each other?" The students are expected to discuss the question with whoever is at a convenient distance. Almost always, an animated class-wide discussion ensues; nearly all students are actively engaged in comparing their answers, arguing for their point of view, and listening critically to their neighbors' reasoning. The instructor does not rush to press for an answer. A minute or more might elapse before a decreased intensity of discussion is noticed. Perhaps the instructor gives a warning, "another $30 \mathrm{sec}-$ onds." At a certain point, all students are asked to give their response. Often, the students will have reached a consensus: nearly everyone now has the same answer. Sometimes, how- ever, the split in opinion persists; that is a signal that more discussion - with some additional exercises and questions-is probably needed.

If student opinion remains divided and a split vote persists despite the student discussion, we will often ask for an A supporter to present his/her argument, followed by a proponent of the $C$ viewpoint. If necessary, we will eventually step in to alleviate the confusion. By this time, most of the students will have carefully thought through the problem. If they haven't already figured it out by themselves, they will now at least be in an excellent position to make sense out of any argument we offer to them. Before those minutes of hard thinking, we could have made the same argument and watched as almost every student in the class gave the wrong answer to some simple question. We know this to be true because we have tried it often enough.

One of the results of using interactive lectures is that the instructor begins to acquire startling new insights into what the students are really getting out of a typical lecture. One can present a straightforward concept (from the instructor point of view) and a simple example, and then-instead of proceeding rapidly to the next topic as would a traditional lecturer-present a short set of questions for the students to answer. One often discovers that the students are deeply mired in confusion. This is precisely what might occur in the office setting when, in the course of leading the student(s) through a series of questions, the instructor uncovers an unexpected and serious conceptual confusion. A tactical retreat is usually necessary, backtracking to simpler concepts that are more firmly understood by the student; one can then lead once again from the new starting point. This process takes some time but is necessary, because the student could not hope to master the new idea without consolidating his or her understanding of the foundation concepts.

This process is exactly what may be replicated through a fully interactive lecture. By using a properly thought out sequence of questions (often developed on the fly without having been scripted in advance) along with the student response system, the instructor is able to identify an area of conceptual confusion. Recognizing the need to retreat, the instructor offers another question that refers back to concepts previously discussed. One may then probe to locate a region of relatively firm understanding that can serve as a new launching point toward the original target.

As we work our way through a series of intermediate questions, at each step, we get a reading on our class: Do they respond quickly? With confidence? Mostly correctly? Then we comment briefly and move forward. Otherwise, we pause for a longer discussion. Instead of disposing of the entire topic in less than 2 min of traditional lecture, we now might take 10-15 min, struggling together with our students as they work their way through a conceptual minefield.

\section{Follow-up activities}

The sequence of interactive questions may be followed by another such sequence, perhaps preceded by a new minilecture. Mini-lectures may also be judiciously sprinkled into a class at various moments, allowing an opportunity for motivational or philosophical comments, or simply to provide a break from problem solving. We also expend considerable amounts of time on student group work using printed worksheets, included as an integral component of the Workbook; an excerpt is in Appendix A. Another method that we have 

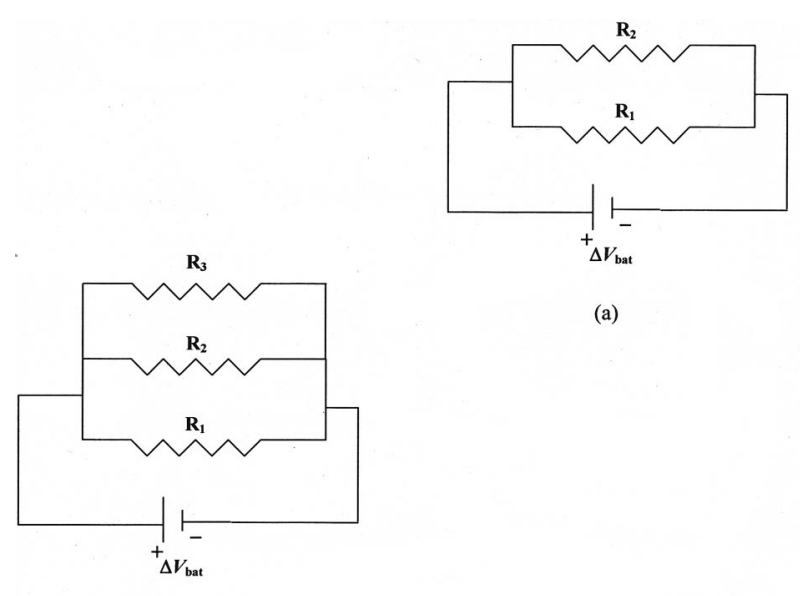

(a)

(b)

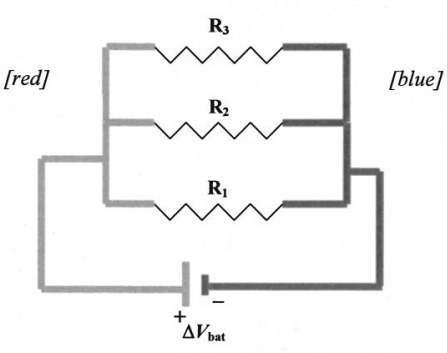

(c)

Fig. 4. Diagrams used in sample interactive-question sequence (Sec. VI): (a) initial diagram; (b) follow-up diagram; (c) diagram representing mnemonic for circuit potential map (instructor statement 9): left-side conducting segments (light shade; referred to as "red" by instructor) are at potential of positive battery terminal, right-side conducting segments (dark shade; referred to as "blue") are at potential of negative battery terminal.

used with great success is to convert the standard physics lecture demonstration into a fully interactive sequence. ${ }^{17}$

Our worksheets designed for use in large-enrollment classes focus on qualitative questions or problems that require only elementary algebraic calculations. Responses required from students include simple sketches, diagrams, graphs, and elementary numerical or algebraic expressions. Such responses may be easily and rapidly scanned and evaluated by an instructor who walks through the room. ${ }^{78} \mathrm{By}$ quickly sampling a significant fraction of the class, the instructor is able to recognize common difficulties and offer appropriate hints or other guidance.

\section{SAMPLE INTERACTIVE-QUESTION SEQUENCE}

The instructional sequence that follows below occurred during the first half of an actual class. After having already studied series and parallel circuits, as well as electrical power, the students had started a new worksheet in the tutorial session on the previous day. The teaching assistant had reported substantial confusion, and so the instructor began class this day by posing a question (Instructor Statement 1) regarding battery power in a parallel circuit.

The instructor asks students to consider the two-resistor parallel circuit shown in Fig. 4(a), and then proceeds to ask a sequence of questions as follows.

(1) Instructor: Suppose an additional resistor is added in parallel to the circuit shown [in Fig. 4(a)], and so we get the circuit shown [in Fig. 4(b)]. Will the power produced by the battery (A) increase, (B) decrease, or (C) remain the same? [The instructor writes the question and the three response options on the board, and follows the same procedure with all questions cited in this segment.]

Students' responses are split approximately equally among the three options.

(2) Instructor: Will the current through the battery (A) increase, (B) decrease, or $(\mathrm{C})$ remain the same?

Student responses are split approximately equally between $(A)$ increase, and $(B)$ decrease.

(3) Instructor: Okay, how about this: is $\Delta V_{R_{3}}$ (A) greater than, (B) less than, or (C) equal to $\Delta V_{R_{2}}$ ? Note: $\Delta V_{R_{3}}$ represents the absolute value of the potential drop across resistor $R_{3}$, etc.

Students are slow to show their flash cards; responses are still very split among the options.

(4) Instructor: Okay, let's go back to the two-resistor circuit [Fig. 4(a)]. Is $\Delta V_{R_{2}}$ (A) greater than, (B) less than, or (C) equal to $\Delta V_{R_{1}}$ ?

Student question: Is $R_{2}=R_{1}$ ?

(5) Instructor: Let's assume they are.

The large majority of students correctly answer $(C)$.

(6) Instructor: Okay, now assume that $R_{2}>R_{1}$; what will be the answer in that case?

Again, the large majority of students correctly answer (C).

(7) Instructor: What happens to $I_{1}$ if we increase $R_{2}$, will it (A) increase, (B) decrease, or (C) remain the same? $I_{1}$ represents the current through resistor $R_{1}$, etc.

The large majority of students correctly answer $(C)$.

(8) Instructor: All right, now let's go back to the threeresistor case. Is $\Delta V_{R_{3}}$ (A) greater than, (B) less than, or (C) equal to $\Delta V_{R_{2}}$ ?

Flash cards are slow coming up, responses are mixed.

(9) Instructor: All right, here's a hint. [Instructor uses red chalk to highlight all conducting segments connected directly to positive terminal of battery, and uses blue chalk to highlight all segments connected to negative terminal [Fig. 4(c)]; this mnemonic had been introduced in previous classes to emphasize that the potential difference between any point in the red region and any point in the blue region was equal to the potential difference between the battery terminals, that is, that $V_{\text {red }}-V_{\text {blue }}=\Delta V_{\text {bat }}$. $]$

Now, the large majority of students hold up the correct answer $(C)$.

(10) Instructor: And how about compared to $\Delta V_{R_{1}}$, is $\Delta V_{R_{3}}$ (A) greater than, (B) less than, or (C) equal to $\Delta V_{R_{1}}$ ?

The large majority of students again hold up correct answer $(C)$.

(11) Instructor: Okay.

Student question: So what changes? Doesn't something change?

(12) Instructor: Yes, but not $\Delta V$. Okay, let's assume that all three resistors are equal, $R_{1}=R_{2}=R_{3}$, and let me ask you about the current. Is $I_{3}(\mathrm{~A})$ greater than, (B) less than, or (C) equal to $I_{2}$ ?

Nearly all students correctly answer $(C)$.

(13) Instructor: And is $I_{3}$ (A) greater than, (B) less than, or $(\mathrm{C})$ equal to $I_{1}$ ? 


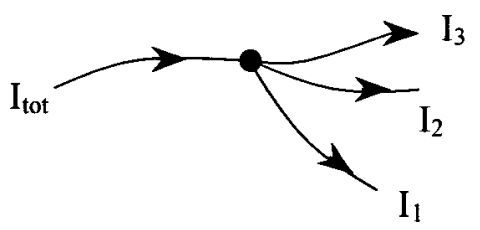

Fig. 5. Diagram used in sample interactive-question sequence (Sec. VI), drawn on board after instructor statement 16 .

Again, nearly all students correctly answer $(C)$.

(14) Instructor: Okay, now if we start with that initial two-resistor circuit and add the third resistor, will the total current through the battery (A) increase, (B) decrease, or (C) remain the same?

Student response is approximately $50 \%$ for $(A), 40 \%$ for $(B)$, and $10 \%$ for $(C)$.

(15) Instructor: Okay, we still have a split vote. Will somebody explain why they think the answer is (A)?

Student: It's (A) because the equivalent resistance of the circuit will decrease.

(16) Instructor: And now will somebody explain why they think the answer is (B)?

Nobody volunteers to defend answer $(B)$. Instructor now draws on board diagram shown in Fig. 5.

(17) Instructor: Okay, once again: If we start with that initial two-resistor circuit and add the third resistor, will the total current through the battery (A) increase, (B) decrease, or $(\mathrm{C})$ remain the same?

Now there is a much larger proportion of correct $(A)$ responses.

(18) Instructor: (A) is correct. I guess that still seems weird.

Several students agree out loud that it does seem weird. Instructor reminds students that they have observed and discussed experiments in the laboratory that are consistent with this conclusion.

Student question: How far can the battery go and still keep putting out more current?

(19) Instructor: I don't know. It basically depends on the equipment you're using.

Student: But aren't you increasing the equivalent resistance, since $R_{\text {equiv }}=R_{1}+R_{2}+R_{3}$ ?

(20) Instructor: Ah. No, that's only for series circuits. It's not true for parallel circuits. Okay, let's go back to our original question. If we add a resistor in parallel to the original two-resistor parallel circuit, will the power produced by the battery (A) increase, (B) decrease, or (C) remain the same?

A full two minutes elapse before the students are asked for a response. The large majority of students correctly answer (A).

(21) Instructor: Okay, (A) is correct.

\section{DISCUSSION OF SAMPLE INTERACTIVE- QUESTION SEQUENCE}

The sequence in Sec. VI is a representative example of how closely a fully interactive lecture may resemble a oneon-one tutorial session, and how little it resembles a traditional lecture. The role of the instructor is essentially that of asking questions, providing hints, and guiding discussion. The instructor also confirms answers on which the class has achieved consensus. Here we discuss key elements of the fully interactive lecture exemplified by this sequence.
A. The frequency of questioning may be as high as several per minute. During this relatively brief sequence, which took only approximately $20 \mathrm{~min}$, the students were asked to use their flash cards to respond to 13 separate questions. During portions of the segment, there were two or three (easy) questions in a single minute. This rate is similar to the rhythm of one-on-one tutoring, in which there is often a rapid exchange of questions and answers between students and instructor.

B. The instructor must often create unscripted questions on the spot. All of the questions were improvised by the instructor without previous scripting or preparation. In just the way that an instructor must come up with appropriate extemporaneous questions when doing one-on-one teaching, an instructor in a fully interactive lecture must be prepared to respond to the flow of the large-class discussion. It is important to write both the question and the answer options on the board so students may refer back to them. However, it may be useful to delay writing the answer options for a few moments to first give students time to consider their own response.

C. Easy questions are used to maintain the flow of the discussion. Many of the questions are easy for the students to answer, and they receive overwhelmingly correct responses. Crouch and Mazur ${ }^{35}$ note that questions with correctresponse rates over $70 \%$ tend to produce less useful discussions than do more difficult questions. However, we find that they build student confidence and are important signals to the instructor of students' current knowledge baseline. Often enough, questions thought by the instructor to be simple turn out not to be, requiring some backtracking. Because of that inherent degree of unpredictability, some proportion of the questions asked will turn out to be quite easy for the students. This small conceptual "step-size" allows more precise fine tuning of the class discussion.

D. Virtually any system offers a rich array of possible question variants. Almost any physics problem may be turned into an appropriate conceptual question. By using the basic question paradigms "increase, decrease, remain the same," "greater than, less than, equal to," and "left, right, up, down, in, out," along with obvious variations, it is possible to rapidly create many questions that probe students' qualitative thinking about the system. By introducing minor alterations in a physical system (adding a force, increasing a resistance, etc.), students can be guided to apply their conceptual understanding in a variety of contexts. In this way, the instructor is able to provide a vivid model of the mental approach needed for active learning.

E. The instructor must be prepared to approach a given problem with a variety of possible questioning strategies. It often is found that students do not respond in an expected manner, and that their knowledge base for a particular problem is shakier than anticipated. Just as in one-on-one tutoring, the instructor must be ready to pose easier questions set in less complex physical settings, and to offer appropriate hints to guide the students toward the target concept. By remaining observant of students' rapidity in offering responses, body language in showing the flash cards, and expressions on their faces, the instructor should be able to judge which questions might require additional response time. 


\section{STUDENT WORKBOOK}

\section{A. Elements of the Workbook}

As our experience in implementing these methods has evolved, we have found it increasingly necessary to abandon traditional curricular materials and to develop our own in order to support the instructional techniques. The first need was for a large stock of appropriate multiple-choice questions to be used in the fully interactive lectures. Despite the excellent set of ConcepTests provided in Mazur's book, our methods required many more questions covering a wider range of difficulty levels than were available in Mazur's book or in other sources. The materials we eventually developed for the second semester of the algebra-based general physics course now form the Workbook for Introductory Physics. ${ }^{79}$

Our early attempts to rely on standard textbooks as a course reference eventually foundered due to the sharp clash between the heavily mathematical approach of such texts, and our strong focus on qualitative and conceptual problems. This clash led to abandonment of a standard text for use in our second-semester course, and the creation of a set of lecture notes as a substitute. These notes, now included as an integral component of the Workbook, emphasize qualitative reasoning, make heavy use of sketches and diagrams, andthough treating fewer topics than standard texts-go into far greater depth on those key concepts chosen for emphasis in our course.

Another key element that was found to be necessary for our Workbook was the creation of numerous free-response worksheets (see, for example, Appendix A). The worksheets emphasize qualitative questions, often require explanations of reasoning, and target learning difficulties that have been identified in the research literature as well as those familiar to us from our own experience. In addition to in-class use, the worksheets also serve as a primary source of homework exercises. Although superb worksheets based on extensive research are available in the Tutorials for Introductory Physics ${ }^{61}$ there was simply not enough to satisfy our need for every-day use in the algebra-based course, covering the full range of topics in that course and appropriate for students even with very low levels of preparation. (Other sources of worksheets of a somewhat different type are now also available. ${ }^{29,30,80}$ )

A final element now included in the Workbook is a large collection of quizzes and exams (and solution sets for the exams) that have been given in previous years. These form an invaluable source of additional flash-card questions, freeresponse exercises, and material for homework assignments and student review. They also respond directly to incessant student demands for samples of previous exams for exam preparation and review.

\section{B. Nature of the curricular materials}

The materials are designed based on the assumption that the solution of even very simple physics problems invariably hinges on a lengthy chain of concepts and reasoning. The question sequences guide the student to lay bare these chains of reasoning, and to construct in-depth understanding of physical concepts by step-by-step confrontation with conceptual sticking points. Carefully linked sequences of activities first lead the student to confront the conceptual difficulties, and then to resolve them. This strategy was developed at the University of Washington. ${ }^{8-10}$ Complex physical problems are broken down into conceptual elements, allowing students to grapple with each one in turn and then return to synthesize a unifying perspective.

Over several years the flash-card questions, worksheets, and quiz and exam problems have undergone a continuous (and unending) process of testing and revision in actual classroom situations. Constant in-class use discloses ambiguous and confusing wording which is then rapidly corrected in new printings of the materials - sometimes the same day, for use in a later tutorial session. Analysis of assessment data provides additional guidance for revisions.

\section{IMPLEMENTATION ISSUES}

\section{A. Constraints on topical coverage}

The single greatest concern for most instructors who are considering implementing interactive-lecture methods is that of coverage: can one cover the same amount of material as in a traditional course? The short answer is no. That is, the instructor will not be able to present, at the board, the same amount of material as in a standard course, and there will not be enough time during class to discuss the usual wide variety of topics. It is helpful to be very clear about this fundamental reality.

However, that short answer only scratches the surface of the issue. For one thing, there is extensive evidence that although instructors in introductory physics courses might cover many topics, the majority of students do not gain any significant degree of mastery over most of the material. Assessment data from our courses and from many others show convincingly that student learning of basic concepts is improved with interactive-engagement methods. Moreover, as much as we might wish to give a clear-cut answer to the question of coverage, there really does not exist an answer that is both accurate and general. The amount of material that can be covered is critically dependent on the student population. We found, for instance, that an amount of material requiring virtually the entirety of a fifteen-week semester at one institution could be effectively covered before the midterm date at a different institution. There, the better-prepared students were able to master the concepts more quickly.

The best response to this question is that instructors are free to cover as many topics as they wish. The real issue is depth of coverage. We choose certain concepts from each topic - the big ideas in our view_and focus in-depth class discussion on those concepts. We are content to discuss only briefly, if at all, other concepts contained within the same topical area. For instance, we cover dc circuits, but not ac circuits or multiloop circuits requiring analysis with simultaneous linear equations. We cover interference, but not diffraction, the optics of lenses, but not of mirrors or optical instruments. We omit topics such as special relativity, particle physics, and astrophysics. (On a time-per-topic basis, our second-semester course spends approximately $75 \%$ on electricity and magnetism and about $25 \%$ on optics and modern physics.) If it is necessary for some reason to cover certain topics, there is nothing to prevent an instructor from devoting a few traditional lectures to those subjects; that will ensure rapid coverage indeed!

\section{B. Consistency of implementation}

In a traditional lecture class the initiative lies entirely with the instructor; the student is free to relax, listen, and pas- 
sively observe the instructor's board work. In the fully interactive lecture the student is continually being forced to think hard about difficult concepts, commit to decisions about problem solutions, and interact with classmates to discuss challenging questions. At the very least this interaction requires a significant investment of thought and energy in a course most students take merely to satisfy a requirement. Many students who find themselves in this situation do not automatically welcome the opportunity to engage in a learning experience that is far more intensive than normal. ${ }^{81,82}$

Largely for these reasons, we and others have found that it is critical to the success of these methods that they be implemented consistently throughout the course, beginning with the very first day. For example, our students pick up their sets of flash cards as they walk in the first day of class, and the first set of flash-card questions begins within the first minute of class. (These are questions such as "Did you take high-school physics?," etc.) We explain that these methods have been repeatedly demonstrated to yield positive results, and reassure students that the impact on grades is usually found to be favorable. Virtually every class period includes interactive questions and related activities. Instructors need to be aware that attempting to introduce these or other forms of active-learning methods mid-semester, after students have already settled down into the routine of a traditional lecture course, could be disastrous for student (and instructor) morale.

\section{Grade-related assessment}

As has been pointed out by many educators, it is absolutely essential to the success of any instructional method that students be examined and graded in a manner consistent with the form of instruction. In our second-semester course, we give a written in-class quiz twice per week; the majority of questions are very similar to the flash-card questions. Indeed, actual past quiz questions are frequently used as part of the flash-card question sequences. Exams also focus heavily on qualitative questions, and on problems that involve little algebra but require good conceptual knowledge and proportional reasoning skills. Some problems require explanations of students' reasoning. To help promote a cooperative atmosphere among the students, an absolute grading scale is used so that any student accumulating a preset point total is guaranteed in advance, at the minimum, a certain corresponding letter grade.

\section{Student attitudes}

We and others ${ }^{35}$ have found that during the first few weeks many students are unsettled and uncomfortable with interactive lecture classes. It takes time for them to become accustomed to the new routine and to appreciate its benefits. We find that by the end of the course, most students have positive attitudes. End-of-course surveys show that most students react favorably to the instructional methods, with approximately 30\%-40\% giving maximum ratings on evaluations. (Sample comment: “... best physics instructor I have ever had.... He makes physics fun and interesting to learn....") Most of the remainder are positive or neutral, but there is often a core of less than $10 \%$ that despises these methods. (Sample comment from the same class: "... has a new way of teaching he is trying to develop. It doesn't work...going to lecture was pointless other than to take required quizzes.") During the Fall 2000 semester at ISU the number of re- sponses in this most unsatisfied category dropped to zero but it appears, unfortunately, that that was only an anomaly.

\section{E. Demands on the instructor}

Teaching a physics course using fully interactive lectures is not an easy task; it requires much energy and commitment. The instructor needs to come to class with a clear plantentative though it may be-for that day's intended sequence of questions and activities. Pre-scripted questions must be selected, and additional questions must be prepared as needed. During class the instructor must be attentive to student reactions, willing to walk around the room and check on student work, and prepared to shift gears and redirect discussion on short notice. (When we find ourselves lecturing for more than ten minutes at a time, it indicates that we have not prepared adequately for that day's class.)

\section{ASSESSMENT OF STUDENT LEARNING}

We first note a remarkable effect that we have consistently observed, that is, a very small number of dropouts, typically $1 \%-3 \%$ after the first week. Attendance is $\approx 90 \%$ on virtually every class day (no doubt largely due to frequent graded quizzes). We should also acknowledge that, although we believe that the techniques would scale well with larger classes, we have not personally tested these methods in classes with over 100 students.

The Workbook has been used for the past five years at SLU and ISU and has undergone continuous development. The course at SLU consisted only of the interactive lectures, while that at ISU has the very substantial additional element of a weekly tutorial session. There are still other important elements of the ISU course that certainly contribute to the learning gains, including the four active-engagement laboratory sessions. (We have no way of apportioning learning gain contributions among the various course elements.) Our full implementation model has been used only for the secondsemester algebra-based course, and data from that course are reported here.

We discuss the results of the Conceptual Survey in Electricity (CSE), the Conceptual Survey in Electricity and Magnetism (CSEM), ${ }^{7}$ electric circuit concept questions, and quantitative problem solving. Since 1997, an abridged version of the CSE has been administered on both the first and last days of class. The CSE is a 33-item multiple-choice test that surveys knowledge related to electrical fields and forces. About half of the items are identical (or nearly so) to questions included on the CSEM. The items on the CSE and CSEM are almost entirely qualitative and probe knowledge both of physics concepts and aspects of related formalism. ${ }^{7}$ On the pre-test, students answered all questions, but on the post-test they were instructed to respond only to a 23-item subset. ${ }^{83}$ We refer to this subset of the CSE as the Abridged CSE. Only the 23 designated items were graded, both on the pre- and post-test. Table I gives these scores for the five courses in which we administered the test; only students who took both tests are included (that is, data are "matched"). Despite the addition of tutorials, along with expansions and improvements in the curricular materials, we cannot conclusively state that the improvements in post-test scores and normalized gain ${ }^{84}$ (that is, Hake's $\langle g\rangle$ ) observed at ISU can be entirely attributed to changes in instruction. ("Normalized gain" is defined as the actual pre-test to post-test increase in exam score, divided by the maximum possible increase.) As 
Table I. Scores on the 23-item abridged Conceptual Survey in Electricity (CSE).

\begin{tabular}{lcccc}
\hline \multicolumn{1}{c}{ Sample } & $N$ & $\begin{array}{c}\text { CSE mean } \\
\text { pre-test score }\end{array}$ & $\begin{array}{c}\text { CSE mean } \\
\text { post-test score }\end{array}$ & $\langle g\rangle^{\mathrm{a}}$ \\
\hline $\begin{array}{l}\text { SLU 1997 } \\
\text { (lecture only) }\end{array}$ & 58 & $29 \%$ & $62 \%$ & 0.46 \\
$\begin{array}{l}\text { SLU 1998 } \\
\text { (lecture only) }\end{array}$ & 50 & $27 \%$ & $66 \%$ & 0.53 \\
$\begin{array}{l}\text { ISU 1998 } \\
\text { (lecture+ tutorial) }\end{array}$ & 70 & $34 \%$ & $76 \%$ & 0.64 \\
$\begin{array}{l}\text { ISU 1999 } \\
\text { (lecture+tutorial) }\end{array}$ & 87 & $30 \%$ & $78 \%$ & 0.69 \\
$\begin{array}{l}\text { ISU 2000 } \\
\text { (lecture+ tutorial) }\end{array}$ & 66 & $34 \%$ & $79 \%$ & 0.69 \\
\hline \hline
\end{tabular}

${ }^{a}$ Calculated using exact (unrounded) pre-test and post-test scores.

one of us has shown (DEM) in a recent report, various other factors probably play a significant role in determining student performance as reflected in assessment data of this type. $^{85}$

In all cases, our pre-test to post-test gains are quite high by most standard measures such as normalized gain $\langle g\rangle(0.46-$ $0.69)$ and effect size. ("Effect size" is the change in exam score divided by the standard deviation of the scores.) By way of comparison, it has been found in mechanics courses that typical values of normalized gain on the Force Concept Inventory are $\langle g\rangle \approx 0.25$ for traditional courses, and 0.35 $\leqslant\langle g\rangle \leqslant 0.70$ for interactive engagement courses. ${ }^{4,19}$ (The Force Concept Inventory is a very widely used mechanics diagnostic test.) For the three ISU samples, treating the "pretest" and "post-test" populations as distinct, we find effect size $d>3.0$, while values of $d \approx 0.8$ are ordinarily considered large. ${ }^{86}$

Although our post-test and $\langle g\rangle$ values are far higher than comparable values found in a national survey of CSE results, ${ }^{7}$ it would not be proper to attempt a direct comparison between our abridged-CSE data and other data reflecting administration of the full CSE. Table II shows mean pre-test, post-test, and normalized learning gain values for a 14-item subset that consists of all questions included on both the abridged CSE and on the CSEM; only ISU data are available. Also shown are comparable values from the national survey data. ${ }^{7}$ (Note that these latter data are not matched.) These data show that although ISU pre-test scores are very nearly equal to those in the algebra-based courses in the national sample, post-test scores and normalized learning gains are dramatically higher than both algebra-based and calculus-based courses in that sample, with mean normalized learning gains (mean $\langle g\rangle=0.68$ ) triple those found in the national survey $(\langle g\rangle=0.22) .{ }^{87}$ We note also that our students' scores on final-exam magnetism questions drawn from the CSEM-well above those of the national sample post-testsare quite consistent with the data shown in Table II.

In Table III we present data on electric circuit questions that have been administered on our final exams for the past four years; these questions (Fig. 6) are drawn from the study of Shaffer and McDermott. ${ }^{88}$ The authors report assessment data on these questions for several different courses, including both traditional courses and courses that used the electric circuit tutorials from Tutorials in Introductory Physics. Although we find significant year-to-year variations in the scores of students in our courses, all of our eight scores are higher than the comparable scores in traditional courses. ${ }^{88}$

Our course differs from most traditional courses in three key ways: (1) use of fully interactive lecture and highly interactive tutorials, (2) strong emphasis on conceptual problems, and (3) coverage of a smaller number of topics than most courses. Our data do not allow us to estimate the relative contribution of these three factors to the assessment results reported here. In relation to item (3), we note that Hake has concluded that the fraction of course time devoted to the study of mechanics topics is not significantly related to superior learning gains on the Force Concept Inventory reported for IE courses. ${ }^{89} \mathrm{He}$ also notes that only partial implementation of interactive methods-even when there may be some emphasis on conceptual problems-is correlated with poorer learning gains than those achieved in courses with full implementation of those methods. ${ }^{90}$ However, a study by Greene suggests that improved learning gains may be possible even in a relatively traditional noninteractive course in which conceptual examples and problems are strongly emphasized on homework assignments and exams. $^{91}$

An important issue for many students in the algebra-based physics course is preparation for pre-professional exams such as the Medical College Admissions Test (MCAT). The most recent versions of the MCAT put substantial emphasis both on qualitative physics questions and on the analysis of complex reading passages requiring application of fundamental physics concepts in unfamiliar contexts. Physics courses that emphasize conceptual understanding might well provide superior preparation for this type of exam. Careful studies of MCAT performance for students enrolled in such a course at the University of California at Davis provide support for this hypothesis. ${ }^{92}$

An important concern of many physics instructors is the

Table II. Scores of CSEM subset of 14 electricity questions.

\begin{tabular}{lcccc}
\hline \hline \multicolumn{1}{c}{ Sample } & $N^{\mathrm{a}}$ & $\begin{array}{c}\text { CSEM electricity subset } \\
\text { mean pre-test score }\end{array}$ & $\begin{array}{c}\text { CSEM electricity subset } \\
\text { mean post-test score }\end{array}$ & $\langle g\rangle^{\mathrm{b}}$ \\
\hline $\begin{array}{l}\text { National sample (algebra-based courses) } \\
\text { National sample }\end{array}$ & 402 & $27 \%$ & $43 \%$ & 0.22 \\
(calculus-based courses) & 1496 & $37 \%$ & $51 \%$ & 0.22 \\
ISU 1998 & & & & \\
ISU 1999 & 70 & $30 \%$ & $75 \%$ & 0.64 \\
ISU 2000 & 87 & $26 \%$ & $79 \%$ & 0.71 \\
\hline \hline
\end{tabular}

${ }^{\mathrm{a}} N$ for national sample is mean of values reported for each of the 14 individual questions, both pre and post; data from Ref. 7.

${ }^{\mathrm{b} C a l c u l a t e d ~ u s i n g ~ e x a c t ~(u n r o u n d e d) ~ p r e-t e s t ~ a n d ~ p o s t-t e s t ~ s c o r e s . ~}$ 


\begin{tabular}{|c|c|c|c|}
\hline Sample & $N$ & $\begin{array}{c}\text { Four-bulb question } \\
\text { [Fig. 6(a)]: correct } \\
\text { with correct explanation }\end{array}$ & $\begin{array}{c}\text { Five-bulb question } \\
{[\text { Fig. 6(b)]: correct }} \\
\text { with correct explanation }\end{array}$ \\
\hline $\begin{array}{l}\text { Traditional, } \\
\text { algebra-based, } \\
\text { university }\end{array}$ & $\mathrm{a}$ & $<50 \%$ & $\cdots$ \\
\hline $\begin{array}{l}\text { Traditional, } \\
\text { calculus-based, } \\
\text { university }\end{array}$ & a & $<50 \%$ & $15 \%^{\mathrm{b}}$ \\
\hline $\begin{array}{l}\text { Tutorial, } \\
\text { calculus-based, } \\
\text { university }\end{array}$ & a & $>75 \%$ & $45 \%^{c}$ \\
\hline $\begin{array}{l}\text { Tutorial, } \\
\text { calculus-based, } \\
\text { college }\end{array}$ & a & $65 \%$ & $\cdots$ \\
\hline SLU 1998 & 61 & $54 \%$ & $59 \%{ }^{\mathrm{d}}$ \\
\hline ISU 1998 & 76 & $75 \%$ & $33 \%$ \\
\hline ISU 1999 & 86 & $59 \%$ & $31 \%$ \\
\hline ISU 2000 & 79 & $86 \%$ & $46 \%$ \\
\hline
\end{tabular}

${ }^{a}$ Four-bulb question, four classes, total $N \approx 500$; Five-bulb question: see notes (b) and (c); data as reported in Ref. 88.

${ }^{\mathrm{b}} N \approx 50$; administered in subsequent course.

${ }^{\mathrm{c}} N \approx 50$; administered in subsequent course.

${ }^{\mathrm{d}}$ Explanation not required.

extent to which a course's focus on conceptual questions may detract from students' ability to solve standard quantitative problems. (We stress, though, that our course's emphasis on qualitative problems is accompanied by extensive practice with some fairly standard quantitative problems, albeit ones requiring only a modest degree of algebraic ma-

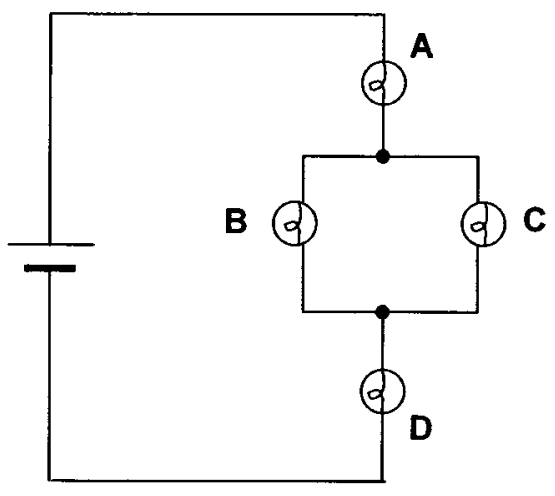

(a)

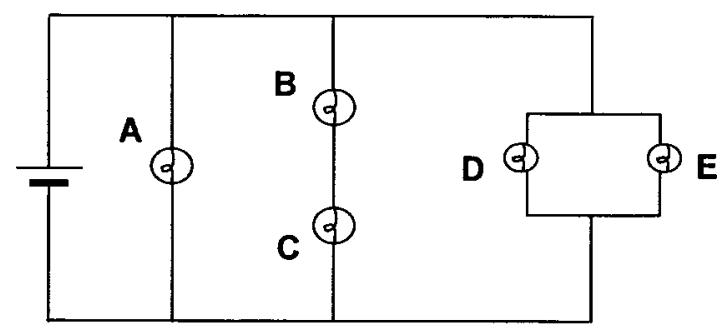

(b)

Fig. 6. Questions used to assess understanding of circuits (from Ref. 88). All bulbs are identical, and all batteries are ideal. Students are asked to rank relative brightness of bulbs, and to explain their reasoning; (a) Answer: A $=\mathrm{D}>\mathrm{B}=\mathrm{C}$; (b) Answer: $\mathrm{A}=\mathrm{D}=\mathrm{E}>\mathrm{B}=\mathrm{C}$. nipulation; see Appendix B. ${ }^{93}$ ) We have attempted to address this concern by including on our final exam problems drawn directly from the traditional calculus-based introductory physics course at ISU (omitting problems using calculus). In 1998 we used six questions copied directly from two different final exams in the calculus-based course; in 1999 and 2000 we included three of those same six questions. (All six are shown in Appendix C.) The data in Table IV show that students in our algebra-based course outperformed the students in the calculus-based course on those questions; they also show that results on the three-item subset were virtually identical to those on the full six-item set.

Our results are consistent with those of others who have implemented research-based instructional methods. That is, students' ability to solve quantitative problems is maintained or even slightly improved. At the same time, at the cost of a modest restriction of topical coverage, students are able to meet substantially more rigorous standards on qualitative problem solving. ${ }^{94}$

Table IV. Scores on quantitative problems, ISU courses.

\begin{tabular}{lcc}
\hline \hline \multicolumn{1}{c}{ Sample } & $N$ & Mean score \\
\hline $\begin{array}{l}\text { Traditional calculus-based course, } \\
1997 \text { and } 1998\end{array}$ & 320 & $56 \%$ \\
six final exam questions & & \\
$\begin{array}{l}\text { Interactive-lecture course, } 1998 \\
\text { (algebra-based) } \\
\text { six final exam questions }\end{array}$ & 76 & $77 \%$ \\
$\begin{array}{l}\text { Traditional calculus-based course, } \\
1997 \text { and 1998 } \\
\text { three-question subset }\end{array}$ & 372 & $59 \%$ \\
$\begin{array}{l}\text { Interactive-lecture course, } \\
\text { 1998, 1999, 2000 } \\
\text { (algebra-based) } \\
\text { three-question subset }\end{array}$ & 241 & \\
\hline \hline
\end{tabular}




\section{CONCLUSION}

Our objective is to transform the large-enrollment lecture classroom, as much as possible, to one that is more typical of small-group instruction. We try to achieve this objective by obtaining simultaneous responses from all students to carefully designed sequences of questions emphasizing qualitative reasoning. The students' responses allow us to modify the pacing and direction of further class discussion and questioning. Curricular materials designed to facilitate this instructional method have been developed, tested, and assembled into a student workbook. Assessment data regarding student learning show gains far higher than those reported in national surveys of comparable courses.

Our experience and those of others makes it clear that interactive lectures are now a practical and tested option, available for immediate use by physics instructors virtually anywhere. As with any other novel teaching method, there is a learning curve for both students and instructors, but most practitioners have found that a commitment to use the methods on an extended basis almost always results in at least some degree of success.

\section{ACKNOWLEDGMENTS}

Dan McCarthy edited an early version of the Workbook with painstaking care and offered many helpful suggestions for improvements. We are very grateful to the teaching assistants at Iowa State University: Michael Fitzpatrick, Tina Fanetti, Jack Dostal, Ngoc-Loan Nguyen, Agnès Kim, Sarah Orley, and David Oesper. Through close and dedicated work with students in their tutorial sessions, they were able to provide much valuable insight into student thinking and many important suggestions for improvements to the curricular materials.

\section{APPENDIX A: EXCERPT FROM FREE-RESPONSE WORKSHEET}

\section{Torque on a Current Loop in a Magnetic Field}

1. All throughout the boxed region below, there is a uniform magnetic field pointing into the page (as indicated by the cross). [This field is created by source currents outside of the region.] A wire segment carrying a current in the direction shown is placed inside the region. [Wires leading to the battery are not shown in this or in any subsequent figure.]

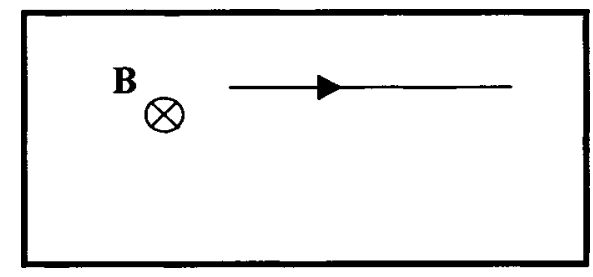

Indicate the direction of the force on the wire segment, using either arrows or the "dot" or "cross" symbols. If the force is zero, write "zero."

2. Now, a square wire loop carrying a steady clockwise current is placed in the region. (Current in each of the four sides is equal.) On each of the four sides of the loop, indicate the direction of the magnetic force (if there is one) or write "zero." Is there a net force acting on the loop as a whole? If so, state its direction. If not, explain how you can tell.

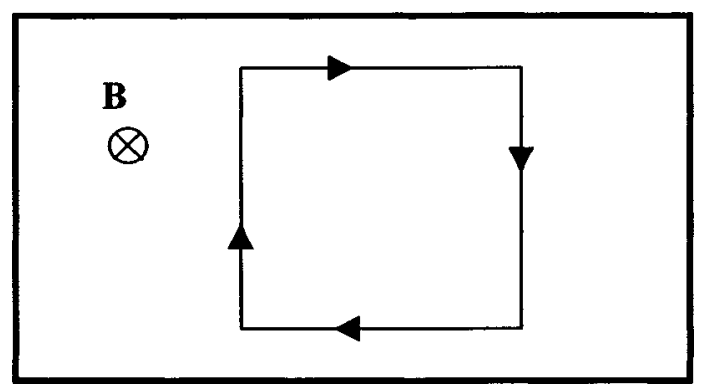

3. In this region, a uniform magnetic field is present that points toward the bottom of the page. A wire segment carrying a current in the direction shown is placed in the region. Indicate the direction of the force on the wire segment, using either arrows or the "dot" or "cross" symbols. If the force is zero, write "zero."

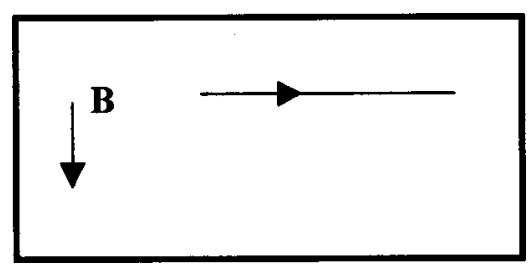

4. Now, a square wire loop carrying a clockwise current is placed in the region. On each of the four sides of the loop, indicate the direction of the magnetic force (if there is one.) Is there a net force acting on the loop as a whole? If so, state its direction. If not, explain how you can tell.

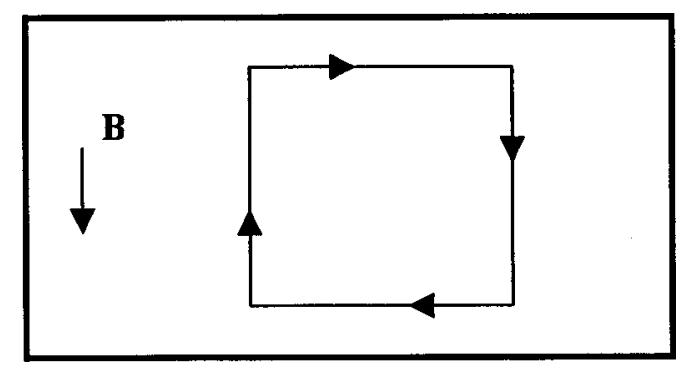

\section{APPENDIX B: REPRESENTATIVE SAMPLE OF QUIZ AND EXAM PROBLEMS USED IN COURSE}

1. An electron is located at $(0 \mathrm{~m},+1 \mathrm{~m})$ and two protons are located at $(0 \mathrm{~m},-2 \mathrm{~m})$. A $+2-\mathrm{C}$ charge is located at the origin. What is the magnitude of the net electric field experienced by the charge at the origin, produced by the electron and the protons?

2. Current flows out of a battery and into resistor $A$ ( $2 \mathrm{ohms}$ ). When the current flows out of resistor $A$ it branches, with part of it going through resistor $B(2 \mathrm{ohms})$ and the rest going through resistor $C$ (4 ohms). The current then recombines and returns to the battery. If the voltage drop across resistor $A$ is $\Delta V_{A}$, what is the voltage drop across resistor C? 

A. $1 / 3 \Delta V_{A}$
B. $\frac{1}{2} \Delta V_{A}$
C. $2 / 3 \Delta V_{A}$
D. $\frac{3}{4} \Delta V_{A}$
E. $\Delta V_{A}$
F. $3 / 2 \Delta V_{A}$
G. $4 / 3 \Delta V_{A}$
H. $2 \Delta V_{A}$
I. $3 \Delta V_{A}$

3. A charge $Q$ is fixed at the origin. An object with mass $3 \mathrm{~kg}$ and charge $9 \mathrm{C}$ is held motionless on the $6-\mathrm{V}$ equipotential circle (a distance $r$ from the origin), and then released. (See diagram.) Which of these will be closest to the velocity attained by the object when it is very far (more than 1,000 $r$ ) from the origin?
A. $0 \mathrm{~m} / \mathrm{s}$
B. $2 \mathrm{~m} / \mathrm{s}$
C. $3 \mathrm{~m} / \mathrm{s}$
D. $4 \mathrm{~m} / \mathrm{s}$
E. $6 \mathrm{~m} / \mathrm{s}$
F. $36 \mathrm{~m} / \mathrm{s}$
G. $54 \mathrm{~m} / \mathrm{s}$

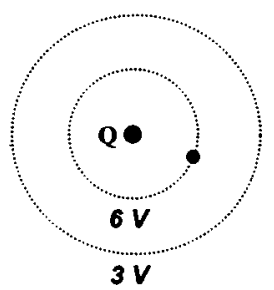

4. A 5-ohm and a 2-ohm resistor are connected in series to a battery. In a separate circuit, a 5-ohm and a 2-ohm resistor are connected in parallel to a battery with the same voltage. In which resistor is the most power being dissipated?

A. The 5-ohm resistor in the series circuit.

B. The 5-ohm resistor in the parallel circuit.

C. The 2-ohm resistor in the series circuit.

D. The 2-ohm resistor in the parallel circuit.

E. Both resistors in the series circuit, which dissipate the same amount of power.

F. Both resistors in the parallel circuit, which dissipate the same amount of power.

G. All four resistors dissipate the same amount of power. 5. A positive charge $q$ is shot into a region in which there is a uniform electric field (see diagram). First, it is shot along path \#1; then it is shot in again along path \#2. CHOOSE TWO CORRECT STATEMENTS (half credit for each).

A. It gains kinetic energy while traveling inside this region.

B. It loses kinetic energy while traveling inside this region.

C. Its kinetic energy is constant while traveling inside this region.

D. The kinetic energy change from [A to B] is greater than the kinetic energy change from [A to $\mathrm{C}]$.

E. The kinetic energy change from [A to $\mathrm{B}]$ is less than the kinetic energy change from [A to $C]$.

F. The kinetic energy change from $[\mathrm{A}$ to $\mathrm{B}]$ is the same as the kinetic energy change from [A to $\mathrm{C}]$.

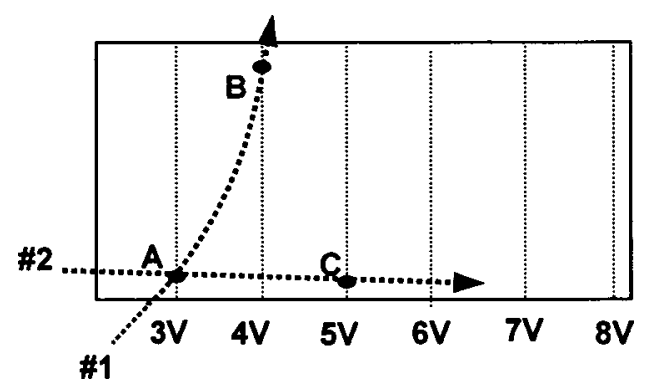

6. The diagram shows part of the path traveled by a particular light ray as it strikes a piece of three-layer material. The different layers have different indices of refraction $\left(\mathrm{n}_{1}, \mathrm{n}_{2}\right.$, and $n_{3}$ ) as indicated. Note that no ray is observed in the $n_{3}$ region.

What is the correct ranking (largest to smallest) of the three indices of refraction?

largest smallest

\section{$\mathbf{n}_{3}$ [no refracted ray in this region}

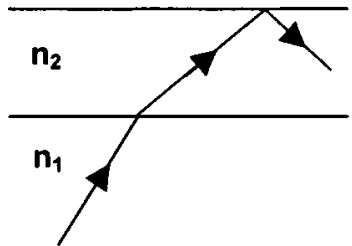

\section{APPENDIX C: QUESTIONS FROM ISU CALCULUS- BASED PHYSICS EXAM}

Questions 1-6 were given on the 1998 final exam in the interactive-lecture course. Questions 1,2, and 4 were also given on the 1999 and 2000 final exams in that course; the format of question 4 was slightly modified to increase its difficulty.

1. Two point charges $+7.00 \times 10^{-9} \mathrm{C}$ and $+9.00 \times 10^{-9} \mathrm{C}$ are located $4.00 \mathrm{~m}$ apart. The electric field intensity (in N/C) halfway between them is:

$\begin{array}{lllll}\text { A. } 0 & \text { B. } 1.1 & \text { C. } 4.5 & \text { D. } 9 & \text { E. } 36\end{array}$

2. Two particles, $\mathrm{X}$ and $\mathrm{Y}$, are $4 \mathrm{~m}$ apart. $\mathrm{X}$ has a charge of $2 \mathrm{Q}$ and $\mathrm{Y}$ has a charge of $\mathrm{Q}$. A third charged particle $\mathrm{Z}$ is placed midway between $\mathrm{X}$ and $\mathrm{Y}$. The ratio of the magnitude of the electrostatic force on $\mathrm{Z}$ from $\mathrm{X}$ to that on $\mathrm{Z}$ from $\mathrm{Y}$ $\left(\mathrm{F}_{\mathrm{zx}}: \mathrm{F}_{\mathrm{zy}}\right)$ is:
A. $4: 1$
B. 2:1
C. $1: 1$
D. $1: 2 \quad$ E. $1: 4$

3. An unknown resistor dissipates $0.50 \mathrm{~W}$ when connected to a $3.0 \mathrm{~V}$ potential difference. When connected to a $1.0 \mathrm{~V}$ potential difference, this resistor will dissipate:
A. $0.50 \mathrm{~W}$
B. $0.17 \mathrm{~W}$
C. $1.5 \mathrm{~W}$
D. $0.056 \mathrm{~W}$

E. None of these.

4. In the diagram, the current in the $3.0-\Omega$ resistor is $4.0 \mathrm{~A}$. The potential difference between points 1 and 2 is:
A. $0.75 \mathrm{~V}$
B. $0.8 \mathrm{~V}$
C. $1.25 \mathrm{~V}$
D. $12 \mathrm{~V}$
E. $20 \mathrm{~V}$

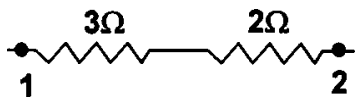

5. The electric field at a distance of $10 \mathrm{~cm}$ from an isolated point charge of $2 \times 10^{-9} \mathrm{C}$ is:
A. $0.18 \mathrm{~N} / \mathrm{C}$
B. $1.8 \mathrm{~N} / \mathrm{C}$
C. $18 \mathrm{~N} / \mathrm{C}$
D. $180 \mathrm{~N} / \mathrm{C}$
E. None of these 
6. A portion of a circuit is shown, with the values of the currents given for some branches. What is the direction and value of the current i?

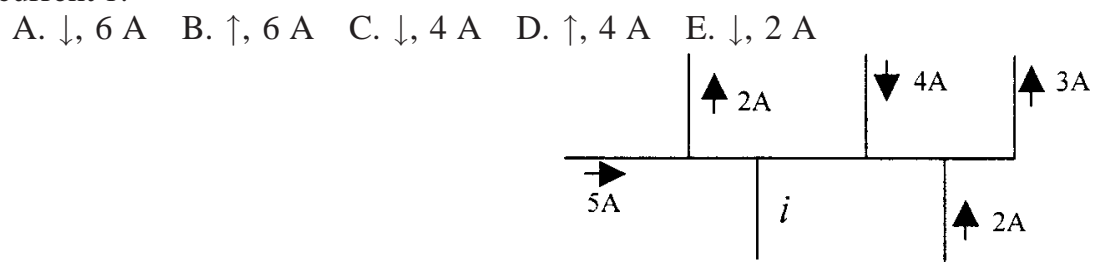

${ }^{a)}$ Electronic mail: dem@iastate.edu

${ }^{1}$ Eric Mazur, Peer Instruction: A User's Manual (Prentice-Hall, Upper Saddle River, NJ, 1997).

${ }^{2}$ Ibrahim Abou Halloun and David Hestenes, "The initial knowledge state of college physics students," Am. J. Phys. 53, 1043-1055 (1985).

${ }^{3}$ David Hestenes, Malcolm Wells, and Gregg Swackhamer, "Force concept inventory," Phys. Teach. 30, 141-158 (1992).

${ }^{4}$ Richard R. Hake, "Interactive engagement versus traditional methods: A six-thousand-student survey of mechanics test data for introductory physics courses," Am. J. Phys. 66, 64-74 (1998).

${ }^{5}$ Edward F. Redish, Jeffery M. Saul, and Richard N. Steinberg, "On the effectiveness of active-engagement microcomputer-based laboratories," Am. J. Phys. 65, 45-54 (1997).

${ }^{6}$ Ronald K. Thornton and David R. Sokoloff, “Assessing student learning of Newton's laws: The force and motion conceptual evaluation and the evaluation of active learning laboratory and lecture curricula," Am. J. Phys. 66, 338-352 (1998).

${ }^{7}$ David P. Maloney, Thomas L. O'Kuma, Curtis J. Hieggelke, and Alan Van Heuvelen, "Surveying students' conceptual knowledge of electricity and magnetism," Phys. Educ. Res., Am. J. Phys. Suppl. 69, S12-S23 (2001). ${ }^{8}$ Lillian C. McDermott, "Millikan Lecture 1990: What we teach and what is learned-closing the gap," Am. J. Phys. 59, 301-315 (1991).

${ }^{9}$ Lillian C. McDermott, "Guest comment: How we teach and how students learn—a mismatch?," Am. J. Phys. 61, 295-298 (1993).

${ }^{10}$ Lillian C. McDermott, "Bridging the gap between teaching and learning: The role of research," in The Changing Role of Physics Departments in Modern Universities: Proceedings of the International Conference on Undergraduate Physics Education, edited by Edward F. Redish and John S. Rigden [AIP Conf. Proc. 399, 139-165 (1997)], pt. 1.

${ }^{11}$ E. F. Redish, "Implications of cognitive studies for teaching physics," Am. J. Phys. 62, 796-803 (1994).

${ }^{12}$ Arnold B. Arons, Teaching Introductory Physics (Wiley, New York, 1997).

${ }^{13}$ David P. Maloney, "Research on problem solving: Physics," in Handbook of Research on Science Teaching and Learning, edited by Dorothy L. Gabel (Macmillan, New York, 1994), pp. 327-354.

${ }^{14}$ Frederick Reif, "Millikan Lecture 1994: Understanding and teaching important scientific thought processes,” Am. J. Phys. 63, 17-32 (1995).

${ }^{15}$ It is widely acknowledged among physics educators that, one way or the other-whether through homework, class work, or individual discussionmost students must be guided to exert intense mental efforts in order to learn physics effectively. Belief in this principle by no means is held only by nontraditional physics educators. Preliminary results from a large-scale interview study clearly suggest that these beliefs characterize the views of many physics instructors regarding student learning of problem solving skills: Patricia Heller, Kenneth Heller, Charles Henderson, Vince H. Kuo, and Edit Yerushalmi, "Instructors' beliefs and values about learning problem solving," in Proceedings of the 2001 Physics Education Research Conference, edited by Scott Franklin, Jeffrey Marx, and Karen Cummings (Rochester, New York, 2001), pp. 75-78.

${ }^{16}$ John R. Thompson, Paula R. L. Heron, Peter S. Shaffer, and Lillian C. McDermott, "Development and assessment of curriculum," AAPT Announcer 28 (2), 80 (1998).

${ }^{17}$ Karen Cummings, Jeffrey Marx, Ronald Thornton, and Dennis Kuhl, "Evaluating innovations in studio physics," Phys. Educ. Res., Am. J. Phys. Suppl. 67, S38-S44 (1999). Also see Ref. 62.

${ }^{18}$ Ronald K. Thornton and David R. Sokoloff, "Learning motion concepts using real-time microcomputer-based laboratory tools," Am. J. Phys. 58, 858-867 (1990).

${ }^{19}$ Edward F. Redish and Richard N. Steinberg, "Teaching physics: Figuring out what works," Phys. Today 52, 24-30 (1999).

${ }^{20}$ Fred Goldberg, "Constructing physics understanding in a computer- supported learning environment," in The Changing Role of Physics Departments in Modern Universities: Proceedings of the International Conference on Undergraduate Physics Education, edited by Edward F. Redish and John S. Rigden [AIP Conf. Proc. 399, 903-911 (1997)], pt. 2.

${ }^{21}$ Raphael Littauer, "Instructional implications of a low-cost electronic student response system," Educational Technology (October 1972), p. 69.

${ }^{22} \mathrm{E}$. A. Lumsden, "Use of student feedback cards for diagnostic purposes during classroom lectures," in Improving College and University Teaching Yearbook 1976 (Oregon State U.P., Corvallis, 1976), p. 39.

${ }^{23}$ A form of the "feedback card" method was described by Thomas A. Moore in his Six Ideas That Shaped Physics (WCB McGraw-Hill, Boston, 1998).

${ }^{24}$ F. Lyman, "The responsive class discussion," in Mainstreaming Digest, edited by A. S. Anderson (College of Education, University of Maryland, College Park, 1981); F. Lyman, "Think-pair-share, thinktrix, thinklinks, and weird facts," in Enhancing Thinking Through Cooperative Learning, edited by N. Davidson and T. Worsham (New York, Teacher's College Press, 1992).

${ }^{25}$ The "minute paper" has long been ascribed to Wilson as he was apparently the first to describe it in the literature [R. C. Wilson, "Improving faculty teaching: Effective use of student evaluations and consultants," J. Higher Educ. 57, 192-211 (1986)]. More recently, it has been acknowledged that the original source of the idea was Berkeley physicist C. Schwartz. See Barbara Gross Davis, Lynn Wood, and Robert C. Wilson, A Berkeley Compendium of Suggestions for Teaching with Excellence (University of California, Berkeley, 1983, available at http:// teaching.berkeley.edu/compendium/, Suggestion \#95).

${ }^{26}$ Charles C. Bonwell and James A. Eison, "Active learning: Creating excitement in the classroom," ASHE-ERIC Higher Education Report No. 1, The George Washington University, School of Education and Human Development, Washington, DC, 1991), pp. 7-19 and passim, and references therein.

${ }^{27}$ Alan Van Heuvelen, "Learning to think like a physicist: A review of research-based instructional strategies," Am. J. Phys. 59, 891-897 (1991).

${ }^{28}$ Alan Van Heuvelen, "Overview, case study physics," Am. J. Phys. 59, 898-907 (1991)

${ }^{29}$ Alan Van Heuvelen, ALPS Kit: Active Learning Problem Sheets, Mechanics (Hayden-McNeil, Plymouth, MI, 1990).

${ }^{30}$ Alan Van Heuvelen, ALPS Kit: Active Learning Problem Sheets, Electricity and Magnetism (Hayden-McNeil, Plymouth, MI, 1990).

${ }^{31}$ Van Heuvelen has updated his methods by incorporating multimedia tools and innovative group activities: Alan Van Heuvelen, "Experiment problems for mechanics," Phys. Teach. 3, 176-180 (1995); "Using interactive simulations to enhance conceptual development and problem solving skills," in The Changing Role of Physics Departments in Modern Universities: Proceedings of the International Conference on Undergraduate Physics Education, edited by Edward F. Redish and John S. Rigden [AIP Conf. Proc. 399, 1119-1135 (1997)], pt. 2; Alan Van Heuvelen, Leith Allen, and Pavlos Mihas, "Experiment problems for electricity and magnetism," Phys. Teach. 37, 482-485 (1999).

${ }^{32}$ Eric Mazur, "Understanding or memorization: Are we teaching the right thing?," in Conference on the Introductory Physics Course, edited by Jack Wilson (Wiley, New York, 1997), pp. 113-123.

${ }^{33}$ Eric Mazur, "Peer Instruction: getting students to think in class," in The Changing Role of Physics Departments in Modern Universities: Proceedings of the International Conference on Undergraduate Physics Education, edited by Edward F. Redish and John S. Rigden [AIP Conf. Proc. 399, 981-988 (1997)], pt. 2.

${ }^{34}$ Catherine H. Crouch, "Peer Instruction: An interactive approach for large classes," Opt. Photonics News 9 (9), 37-41 (September 1998); Adam P. Fagen, Catherine H. Crouch, and Eric Mazur, "Peer instruction results 
from a range of classrooms," Phys. Teach. 40(4), 206-209 (2002).

${ }^{35}$ Catherine H. Crouch and Eric Mazur, "Peer instruction: Ten years of experience and results," Am. J. Phys. 69, 970-977 (2001); http://mazurwww.harvard.edu/library

${ }^{36}$ Laurent Hodges, "Changes in the introductory calculus-based physics course at Iowa State University," in Conference on the Introductory Physics Course, edited by Jack Wilson (Wiley, New York, 1997), pp. 291-294.

${ }^{37}$ R. G. Fuller, "Using interactive lecture methods to teach physics," American Physical Society Forum on Education, Spring 1994.

${ }^{38}$ H. T. Hudson, "Teaching physics to a large lecture section," Phys. Teach. 23, $81-84$ (1985).

${ }^{39}$ Robert J. Dufresne, William J. Gerace, William J. Leonard, Jose P. Mestre, and Laura Wenk, "Classtalk: A classroom communication system for active learning," J. Comp. Higher Educ. 7, 3-47 and http:// umperg.physics.umass.edu/gemsFolder/umperg2/CT_Paper.pdf (1996).

${ }^{40}$ Jose P. Mestre, William J. Gerace, Robert J. Dufresne, and William J. Leonard, "Promoting active learning in large classes using a classroom communication system," in The Changing Role of Physics Departments in Modern Universities: Proceedings of the International Conference on Undergraduate Physics Education, edited by Edward F. Redish and John S. Rigden [AIP Conf. Proc. 399, 1019-1036 (1997)], pt. 2.

${ }^{41}$ Laura Wenk, Robert Dufresne, William Gerace, William Leonard, and Jose Mestre, "Technology-assisted active learning in large lectures," in Student-Active Science, Models of Innovation in College Science Teaching, edited by Ann P. McNeal and Charlene D'Avanzo (Saunders College Publishing, Fort Worth, 1997), pp. 431-452.

${ }^{42}$ J. Poulis, C. Massen, E. Robens, and M. Gilbert, "Physics lecturing with audience paced feedback," Am. J. Phys. 66, 439-441 (1998).

${ }^{43}$ Joel A. Shapiro, "Electronic student response found feasible in large science lecture hall," J. Coll. Sci. Teach. 26, 408-412 (1997).

${ }^{44}$ Ray A. Burnstein and Leon M. Lederman, "Using wireless keypads in lecture classes," Phys. Teach. 39, 8-11 (2001).

${ }^{45}$ Robert J. Beichner, Jeffery M. Saul, Rhett J. Allain, Duane L. Deardorff, and David S. Abbott, "Introduction to SCALE-UP: Student-centered activities for large enrollment university physics," Proceedings of the 2000 Annual Meeting of the American Society for Engineering Education, Session 2380, 2000 and http://www2.ncsu.edu/ncsu/pams/physics/ Physics_Ed/index.html.

${ }^{46}$ Dean Zollman, "Learning Cycle physics," in The Changing Role of Physics Departments in Modern Universities: Proceedings of the International Conference on Undergraduate Physics Education, edited by Edward F. Redish and John S. Rigden [AIP Conf. Proc. 399, 1137-1149 (1997)], pt. 2 .

${ }^{47}$ Priscilla W. Laws, "Calculus-based physics without lectures," Phys. Today 44 (12), 24-31 (1991); "Millikan Lecture 1996: Promoting active learning based on physics education research in introductory physics courses," Am. J. Phys. 65, 14-21 (1997).

${ }^{48}$ David R. Sokoloff and Ronald K. Thornton, "Using interactive lecture demonstrations to create an active learning environment," Phys. Teach. 35 (10), 340-347 (1997).

${ }^{49}$ David R. Sokoloff and Ronald K. Thornton, "Using interactive lecture demonstrations to create an active learning environment," in The Changing Role of Physics Departments in Modern Universities: Proceedings of the International Conference on Undergraduate Physics Education, edited by Edward F. Redish and John S. Rigden [AIP Conf. Proc. 399, 10611074 (1997)], pt. 2

${ }^{50}$ Gregor M. Novak, Evelyn T. Patterson, Andrew D. Gavrin, and Wolfgang Christian, Just-In-Time Teaching: Blending Active Learning with Web Technology (Prentice-Hall, Upper Saddle River, NJ, 1999).

${ }^{51}$ David Hestenes, "Modeling methodology for physics teachers," in The Changing Role of Physics Departments in Modern Universities: Proceedings of the International Conference on Undergraduate Physics Education, edited by Edward F. Redish and John S. Rigden [AIP Conf. Proc. 399, 935-957 (1997)], pt. 2.

${ }^{52}$ Ruth W. Chabay and Bruce A. Sherwood, Electric and Magnetic Interactions (Wiley, New York, 1995).

${ }^{53}$ Bruce A. Sherwood and Ruth W. Chabay, "Integrating theory and experiment in lecture using desktop experiments," in The Changing Role of Physics Departments in Modern Universities: Proceedings of the International Conference on Undergraduate Physics Education, edited by Edward F. Redish and John S. Rigden [AIP Conf. Proc. 399, 1053-1060 (1997)], pt. 2 .

${ }^{54}$ Randall D. Knight, Physics: A Contemporary Perspective (AddisonWesley, Reading, MA, 1997), Vols. 1,2, preliminary ed. Also see Ref. 80.
${ }^{55}$ Ruth W. Chabay, "Qualitative understanding and retention," AAPT Announcer 27 (2), 96 (1997).

${ }^{56}$ Randall D. Knight, "Studio Physics at Cal Poly: What have we learned?" AAPT Announcer 30 (2), 132 (2000).

${ }^{57}$ David E. Meltzer and Kandiah Manivannan, "Promoting interactivity in physics lecture classes," Phys. Teach. 34, 72-76 (1996).

${ }^{58}$ Kandiah Manivannan and David E. Meltzer, "Increasing active student participation in the classroom through the use of "flash cards," " in The Changing Role of Physics Departments in Modern Universities: Proceedings of the International Conference on Undergraduate Physics Education, edited by Edward F. Redish and John S. Rigden [AIP Conf. Proc. 399, 821-822 (1997)], pt. 1; David E. Meltzer, "Nontraditional approach to algebra-based general physics," ibid. 399, 823-824 (1997).

${ }^{59}$ David E. Meltzer and Kandiah Manivannan, "Interactive methods for large classes: Workshop W29 at the AAPT Winter Meeting, New Orleans, Louisiana, January 4, 1998"; David E. Meltzer and Kandiah Manivannan, "Interactive methods for large classes: Workshop W36 at the AAPT Summer Meeting, Lincoln, Nebraska, August 4, 1998," AAPT Announcer 28 (2), 66 (1998); "Workshop W04 at the AAPT Summer Meeting, San Antonio, Texas, August 3, 1999," 29 (2), 57 (1999); "Workshop W11 at the AAPT Summer Meeting, Guelph, Ontario, Canada, July 29, 2000," 30 (2), 53 (2000).

${ }^{60}$ Lillian C. McDermott, Stamatis Vokos, and Peter S. Shaffer, "Sample class on Tutorials in Introductory Physics," in The Changing Role of Physics Departments in Modern Universities: Proceedings of the International Conference on Undergraduate Physics Education, edited by Edward F. Redish and John S. Rigden [AIP Conf. Proc. 399, 1007-1018 (1997)], pt. 2 .

${ }^{61}$ Lillian C. McDermott, Peter S. Shaffer, and the Physics Education Group, Tutorials in Introductory Physics (Prentice-Hall, Upper Saddle River, NJ, 2002).

${ }^{62}$ Patricia Heller, Ronald Keith, and Scott Anderson "Teaching problem solving through cooperative grouping. Group versus individual problem solving," Am. J. Phys. 60, 627-636 (1992).

${ }^{63}$ Patricia Heller and Mark Hollabaugh, "Teaching problem solving through cooperative grouping. 2. Designing problems and structuring groups," Am. J. Phys. 60, 637-644 (1992).

${ }^{64}$ Patricia Heller, Thomas Foster, and Kenneth Heller, "Cooperative group problem solving laboratories for introductory classes," in The Changing Role of Physics Departments in Modern Universities: Proceedings of the International Conference on Undergraduate Physics Education, edited by Edward F. Redish and John S. Rigden [AIP Conf. Proc. 399, 913-933 (1997)], pt. 2.

${ }^{65}$ Patrica Heller and Kenneth Heller, Cooperative Group Problem Solving in Physics (University of Minnesota, Minneapolis, 1999) and http:// www.physics.umn.edu/groups/physed/Research/CGPS/GreenBook.html.

${ }^{66}$ David R. Sokoloff, Ronald K. Thornton, and Priscilla W. Laws, RealTime Physics, Active Learning Laboratories; Module 1: Mechanics; Module 2: Heat and Thermodynamics (Wiley, New York, 1999).

${ }^{67}$ Priscilla W. Laws, with R. J. Boyle, P. J. Cooney, K. L. Laws, J. W. Luetzelschwab, D. R. Sokoloff, and R. K. Thornton, Workshop Physics Activity Guide, The Core Volume with Module 1: Mechanics 1 (Wiley, New York, 1997).

${ }^{68}$ Pamela Ann Kraus, "Promoting Active Learning in Lecture-Based Courses: Demonstrations, Tutorials, and Interactive Tutorial Lectures," Ph.D. dissertation, University of Washington (UMI, Ann Arbor, MI, 1997), UMI \#9736313.

${ }^{69}$ Jack M. Wilson, "The CUPLE physics studio," Phys. Teach. 32, 518-523 (1994).

${ }^{70}$ Classtalk, a hard-wired system, may still be available from Interactive Classroom Consulting, http://www.bedu.com/ICC.html.

${ }^{71} \mathrm{~A}$ system based on infrared signaling is distributed by EduCue, $351 \mathrm{Al}-$ plaus Ave, Alplaus, NY 12008, http://www.educue.com; a different system is available from TI, http://education.ti.com/product/tech/tinav/overview/ overview.html.

${ }^{72} \mathrm{~A}$ rf-based system is available from Socratec.com, http:// www.socratec.com/.

${ }^{73}$ It is possible to use questions that focus on quantitative understanding or methods of calculation. We do so on occasion, depending on the nature of the topic and the course itself. In this regard, see Refs. 40 and 58. The strategy of using an "easy-to-hard" conceptual sequence has also been discussed by Mestre et al., Ref. 40.

${ }^{74}$ This strategy is also emphasized by Crouch and Mazur, Ref. 35 .

${ }^{75}$ See Sec. VIII. We refer to these sessions as "tutorials" because their 
format and philosophy very closely match those developed at the University of Washington. However, for the most part, the materials we employ during these sessions are not the actual Tutorials in Introductory Physics cited in Ref. 61. The latter are used during three of the laboratory periods at ISU.

${ }^{76}$ The Workbook is distributed in three-hole-punched format for ring binders, so students do not have to bring all of the materials every day.

${ }^{77}$ Kandiah Manivannan and David E. Meltzer, "Use of in-class physics demonstrations in highly interactive format," in Proceedings of the 2001 Physics Education Research Conference, edited by Scott Franklin, Jeffrey Marx, and Karen Cummings (Rochester, New York, 2001), pp. 95-98.

${ }^{78}$ The idea of using specially designed worksheets in large lecture classes has also been discussed by Van Heuvelen (Refs. 27 and 28) and by Kraus (Ref. 68). Many questions in our worksheets also ask for explanations of students' reasoning. These explanations are emphasized and carefully checked during the tutorial sessions, but not so much so during the interactive lectures. We have not found it practical to make a rigid separation between worksheets used in lecture and those used in tutorials. In fact, which worksheets get used where is variable, and is essentially a function of day-to-day class scheduling.

${ }^{79}$ A preliminary edition of the Workbook is available from the authors in CD-ROM format. There is now also a vastly expanded inventory of ConcepTests available at the Project Galileo web site, http:// galileo.harvard.edu/.

${ }^{80}$ Randall D. Knight, Physics: A Contemporary Perspective, Student Workbook (Addison-Wesley Longman, Reading, MA, 1997), Vols. 1, 2, preliminary ed.

${ }^{81}$ In fact, this type of student resistance to interactive-engagement physics courses has been discussed in the literature by a number of practitioners, for example, Ruth W. Chabay and Bruce A. Sherwood, Instructor's Manual to Accompany Electric and Magnetic Interactions (Wiley, New York, 1995), pp. 8 and 9.

${ }^{82}$ Additional insight regarding possible gender-related disparities in student responses are discussed by Priscilla W. Laws, Pamela J. Rosborough, and Frances J. Poodry, "Women's responses to an activity-based introductory physics program," Phys. Educ. Res., Am. J. Phys. Suppl. 67, S32-S37 (1999).

${ }^{83}$ The CSE was used in this abridged form, omitting some items, for various reasons. In some cases, the notational conventions differed from what was used in class (for example, electric field lines are used on the CSE, but only field vectors are used in class). In other cases, the questions dealt with material that was covered peripherally or not at all in class. This abridged subset consisted of the following item numbers from CSE Form G [corresponding CSEM item numbers in brackets]: 3, 4, 5, 6, 7, 8, 9[7], 10[8], $11[9], 12,13[10], 14[11], 15,16[12], 23[17], 24[18], 25[19], 26,27[16]$, 28[20], 31[3], 32[4], 33[5]. (In several cases, there are minor differences between the CSE questions and the corresponding CSEM items.)

${ }^{84}$ We follow Hake's definition (Ref. 4) of "normalized learning gain" $g$, where $g=[$ (post-test score-pre-test score)/(maximum possible score-pre- test score)]; $\langle g\rangle$ is calculated by using class-mean values for pre-test and post-test scores in the formula for $g$.

${ }^{85}$ David E. Meltzer, "The relationship between mathematics preparation and conceptual learning gains in physics: A possible 'hidden variable' in diagnostic pretest scores?,' Phys. Educ. Res., Am. J. Phys. Suppl. (submitted), and available at http://www.public.iastate.edu/ per/articles/ms/ms.pdf.

${ }^{86}$ The effect size $d$ is a widely used measure in education research that quantifies the nonoverlap of two populations, typically including one that has, and another that has not received some specified pedagogical intervention. (Higher values of $d$ correspond to greater nonoverlap, that is, larger treatment "effect.") See, for example, Jacob Cohen, Statistical Power Analysis for the Behavioral Sciences (Lawrence Erlbaum, Hillsdale, NJ, 1988), 2nd ed., Chap. 2. The definitions given by Cohen are widely, though not universally, adopted: $d=\left|m_{A}-m_{B}\right| / \sigma_{\text {rms }} ; \quad \sigma_{\text {rms }}$ $=\sqrt{\left(\sigma_{A}^{2}+\sigma_{B}^{2}\right) / 2}$, where $m_{A}$ and $\sigma_{A}$ are the mean score and standard deviation of population $A$, and $m_{B}$ and $\sigma_{B}$ are those corresponding to population $B$. As an example, for the ISU 2000 sample we have $m_{\text {pre-test }}$ $=33.7 \%$ and $\sigma_{\text {pre-test }}=16.0 \%, m_{\text {post-test }}=79.4 \%$ and $\sigma_{\text {post-test }}=14.3 \%$, $\sigma_{\mathrm{rms}}=15.2 \%$, and $d=45.7 / 15.2=3.01$.

${ }^{87}$ Of the 223 students in the three ISU samples combined, only 7 had individual values of $g \leqslant 0.22$.

${ }^{88}$ Peter S. Shaffer and Lillian C. McDermott, "Research as a guide for curriculum development: An example from introductory electricity. II. Design of instructional strategies," Am. J. Phys. 60, 1003-1013 (1992).

${ }^{89}$ Reference 4, Sec. V B 3.

${ }^{90}$ Reference 4 , Sec. III A.

${ }^{91}$ Ronald L. Greene, "Illuminating physics via web-based self-study," Phys. Teach. 39, 356-360 (2001). In Greene's course, very strong emphasis was placed on qualitative, conceptual problems in examples, homework assignments, quizzes, and exams. Although interactive methods were not used during lectures, it is important to note that the extensive homework assignments made heavy use of a nontraditional, highly interactive web-based methodology which itself incorporated IE techniques such as immediate feedback.

${ }^{92}$ C. J. DeLeone, W. H. Potter, and L. B. Coleman, "Comparisons of student MCAT performance: Traditional lecture/laboratory course vs. Physics Education Research based course," APS Centennial Meeting Program, Session LB20, Abstract LB20.07 (1999).

${ }^{93}$ The ratio of quantitative to qualitative problems on our quizzes and exams is approximately $1 / 1$. Many problems are of a combined nature, involving both qualitative and quantitative elements; they often emphasize proportional reasoning in various contexts. During a semester, including quizzes, homework, and exams, students solve approximately 400 problems for grade credit.

${ }^{94}$ Lillian Christie McDermott, "Oersted Medal Lecture 2001: Physics Education Research-The key to student learning," Am. J. Phys. 69, 11271137 (2001). 